\title{
DPD-Based Colorimetric Quantification of Free Available Chlorine (FAC) in Floatation Tank Conditions
}

\author{
Jeffrey H. Ma ${ }^{1}$, Helen J. Heacock-Rivers ${ }^{2}$, Frederick Shaw ${ }^{3}$ \\ 1 Lead author, B. Tech Student, School of Health Sciences, British Columbia Institute of Technology. Email: jma104@my.bcit.ca \\ 2 Supervisor, School of Health Sciences, British Columbia Institute of Technology \\ 3 Contributor, School of Health Sciences, British Columbia Institute of Technology
}

\section{ABSTRACT:}

Background: Floatation tanks are quickly gaining traction as a form of relaxation, with numerous spas emerging in the Lower Mainland and beyond. The tanks are filled with a solution of magnesium sulphate, recycled between client uses. Thus, there exists a potential for microbiological contamination and subsequently, disease transmission. Health inspectors in BC may be involved the approval and inspection process for floatation tank spas; therefore, it is important to ensure that floatation tank environments are not a vehicle for disease. As a preventative measure, guidelines are in place for the halogenation of tank water at a level of 3-5 ppm free available chlorine (FAC). However, there is no standard method for the accurate and reliable quantification of FAC in high salinity environments. This study characterised the effect of high salinity on FAC readings from the $\mathrm{HACH}$ Pocket Colorimeter $\mathrm{II}^{\mathrm{TM}}$, and derived a conversion factor to obtain an accurate reading for inspectors in the field.

Methods: Floatation tank environments were simulated using USP-grade Epsom salts, Clorox ${ }^{\mathrm{TM}}$ bleach, and a hot water bath set at approximately $34^{\circ} \mathrm{C}\left(93^{\circ} \mathrm{F}\right)$. Assuming an initial concentration of $5.25 \%$ sodium hypochlorite, the bleach was serially diluted to obtain concentrations from 1-8 ppm. The final dilution step involved the addition of either $34^{\circ} \mathrm{C}$ water or an Epsom salt solution $\left(\mathrm{MgSO}_{4}\right)$ at a specific density of 1.220 to create two solutions with identical amounts of bleach - one with and one without salt. The solutions were tested for chlorine two minutes later through the addition of DPD - a colorimetric dye that results with FAC - and measuring the colour intensity using the Pocket Colorimeter II. A percentage recovery was derived using the ratio between measured FAC with and without salt.

Results: There was a statistically significant difference $(\mathrm{p}=0.05)$ between measured chlorine levels with and without salt as determined by a paired t-test. Further analysis via ANOVA and a post-hoc multiple comparison test (Scheffe's) indicated a dose-response relationship - increasing the amount of hypochlorite in an Epsom solution results in a statistically significant increase in measured FAC between the following groups: 1-2 ppm, 3-5 ppm, and 6-8 ppm of added hypochlorite. Linear regression revealed a strong correlation (0.97) between measured chlorine with and without salt. Conclusions: The HACH Pocket Colorimeter II $^{\mathrm{TM}}$ can be used to estimate the amount of FAC in a floatation tank solution using a conversion factor of 0.79 ; to obtain an accurate measurement, divide the FAC reading in salt by 0.79 .

Keywords: Floatation tanks, DPD, Pocket Colorimeter II, HACH, testing, free available chlorine, public health inspection, high salinity, Epsom salts 
Floatation tanks have gained considerable popularity over the last 5 years. An assortment of personal service establishments (PSEs) advertise themselves as floatation spas or houses which offer these services. In brief, an individual is placed in a tank or room filled with approximately $17-28 \mathrm{~cm}$ (7-11 in.) of water, typically saturated with $40 \%$ Epsom $\left(\mathrm{MgSO}_{4}\right)$, and lays back. The water is calibrated to the temperature of skin $\left(34^{\circ} \mathrm{C}\right)$, and exerts an upward, buoyant force due to the water's high density $\left(1.25-1.3 \mathrm{~g} / \mathrm{cm}^{3}\right)(1)$. External stimuli are reduced to a minimum, without any light, perception of gravity, or heat transfer between the person and environment. Sounds are also minimized with the utilization of noise-dampening materials present in the tank. Proponents of floatation tanks claim that it creates a relaxing, stimuli-free environment for meditation and facilitates introspection (2).

A typical float tank design is comprised of a submersible pump which shunts water through a mechanical filter into a circulation system. Water gets disinfected by a UV system and is diverted along a transfer line to a heating device before being released back into the tank (3).

If a chemical residual disinfectant is used, circulation ensures that there is constant disinfection and prevents the stagnation of water. BC Ministry of Health guidelines recommend that a residual level of free chlorine or bromine ( $\mathrm{HOCl}, \mathrm{HOBr}$ ) be used as a disinfectant to further discourage the growth of halotolerant organisms (4). Although multiple barriers of pathogen control are utilized, there are some concerns amongst public health practitioners:

- The water is recycled between uses, leading to the potential for disease propagation

- Testing of chlorine content is difficult due to the high salinity, which interferes with all known methods of free chlorine quantification
- There is limited knowledge on what types of organisms can thrive in high salinity water. However, there are some observable patterns acknowledged later in the report.

- There is no standard of operation for float tanks. The National Standards Foundation (NSF) Floatation Tank Working Group has a draft standard (CCS-12804) for entire float tanks to ensure they are safe for use and achieve stipulated disinfection efficacies (5). However, there is currently no legislative requirement in British Columbia for float tanks to have NSF-certified components

Pathogenic organisms of interest in a float tank environment have not been extensively studied; however, the NSF has focused on several that have been implicated in pool borne illness: (6)

TABLE 1. Common pool-borne pathogens and characteristics

\begin{tabular}{ll}
\hline $\begin{array}{l}\text { Waterborne Pathogen } \\
\text { Pseudomonas aeruginosa }\end{array}$ & $\begin{array}{l}\text { Associated morbidity } \\
\text { Waterborne pathogen and } \\
\text { etiological agent for } \\
\text { Pseudomonas-associated } \\
\text { folliculitis (PAF) }\end{array}$ \\
Faecal coliforms & Enteric illness, including diarrhea \\
Legionella pneumophila & $\begin{array}{l}\text { Respiratory infections: } \\
\text { Pontiac fever (minor) }\end{array}$ \\
& Legionellosis (severe) \\
Candida sp. & Yeast infections (e.g. vaginal) \\
Giardial & Enteric protozoa resulting in \\
Cryptosporidium sp. & enteric illness \\
\hline
\end{tabular}

Public health practitioners such as environmental health officers (EHOs) may be involved in assessing whether these tanks are physically, chemically, and microbiologically safe. The following evidence review will briefly examine existing knowledge of pathogen survivability in float tanks, critique past testing methodologies for chlorine in float tanks, and provide clarity on the multifaceted issues surrounding float tank regulation. Further insight will be provided on which methods are currently viable for testing in high 
salinity concentrations, and the potential for knowledge translation into practice by EHOs across the Lower Mainland and beyond.

\section{BRIEF EVIDENCE REVIEW}

\section{Survivability of pathogenic organisms in floatation} tank water

A report by NSF in 2012 tested the susceptibility of selected bacteria and yeast to float tank water $(40 \%$ $\mathrm{MgSO}_{4}$ ) after $0,1,4,8$, and 24 hours of exposure (7). The report concluded that there was over a 2 -log reduction in $P$. aeruginosa after 24 hours. Enterococcus faecium and Candida albicans experienced minor log reductions.

A second report conducted three years later, also by NSF, corroborated with the results from 2012. In contrast to the initial report, the samples were shaken (8). It monitored levels of E. faecium and $P$. aeruginosa and found that $E$. faecium was not affected by high salinity, whereas $P$. aeruginosa had a 2.58-log reduction in 1 hour, and over 6-log reduction over 24 hours. These preliminary reports confirm that circulation plays a pivotal role in disinfection. $P$. aeruginosa achieved much greater log reductions in shaken samples, thus mixing is instrumental for optimal disinfection. However, Epsom salts alone should not be considered an adequate mode of disinfection due to its inability to achieve a 3-log reduction between client uses as recommended by NSF. It should be used in concert with other disinfection protocols such as chlorination. Other sections Furthermore, viruses such as norovirus can be readily inactivated by levels of chlorination as low as $1.0 \mathrm{mg} / \mathrm{L}(9)$.

P. aeruginosa, a gram-negative pathogen, were more susceptible to Epsom water than E. faecium. An adequate hypothesis is that gram-negative cell walls have a considerably thinner peptidoglycan layer compared to their gram-positive counterparts, leading to significantly more water efflux into the extracellular milieu (10). The cell succumbs to the efforts of osmotic pressure and the cell eventually undergoes crenation.
Although only a general guideline, future studies should focus on gram-positive or resilient microbiological species in water including Giardia or Cryptosporidium sp. Alternatively, regulating the use of an NSF/ANSI approved filter as part of the circulation system may help mitigate this issue (5).

\section{Methods of disinfection and testing}

Disinfection of pathogenic organisms occurs via oxidative stress and antimicrobial properties of chemicals. Halogenic compounds are the current de facto standard in disinfection due to their long-term residual and proven bactericidal capabilities (4). These include free chlorine (hypochlorous acid) and free bromine (hypobromous acid). Other disinfection modalities include ozonation, UV, and hydrogen peroxide (11). These do not provide adequate levels of residual disinfection and are only accepted as supplementary modes of disinfection to either chlorination or bromination. Health officials are currently focused on testing for chlorine or bromine levels to determine compliance with provincial guidelines of 3-5 ppm.

\section{Halogen Testing}

Traditional testing is done through colorimetric or photometric means $(12,13)$. Another test involves testing the oxidation-reduction potential to estimate chlorine concentrations, but is not widely used amongst health authorities in $\mathrm{BC}$. This brief evidence review focused on three different kits used in $\mathrm{BC}$ : Taylor, HACH, and ColorQ. All three test kits are widely used in the industry, and a brief analysis was performed based on reproducibility and percentage recovery.

\section{Testing Reliability and Accuracy}

Titration kits are based on colorimetric changes through reaction with various forms of a reagent, DPD (N, N Diethyl-1,4 Phenylenediamine Sulfate), to determine free halogen, total halogen, $\mathrm{pH}$, and total alkalinity $(12,14)$. Quantification is performed by comparing against a colour standard such as the 
Taylor or HACH kits, or via photometric devices such as the Taylor ColorQ test kit.

A report by NSF in 2015 compared DPD-based testing with test strips under float tank conditions consisting of $40 \% \mathrm{MgSO}_{4}$, with free and total chlorine concentrations at 0,2 and 5 ppm (15). Whilst DPD testing had results that were closer to the actual chlorine concentration, the results lacked precision.

In contrast, LaMotte ${ }^{\mathrm{TM}}$ test strips had more consistent results, but lower recovery. The authors conclude that further correlational studies should be done to derive a "conversion factor" between measured and actual free and total chlorine levels.

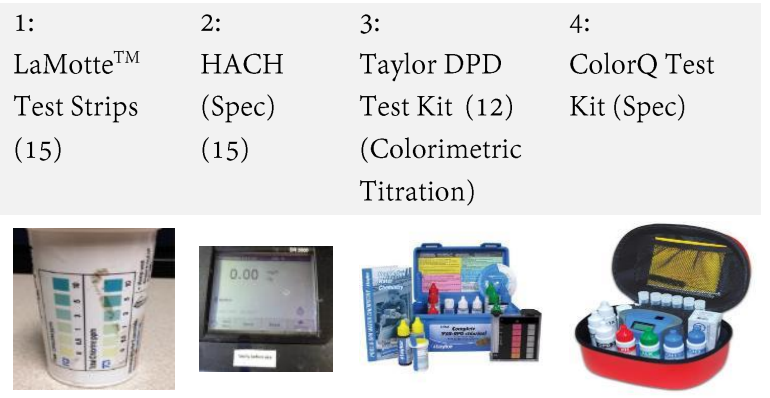

FIG. 1 - Common test kits employ a DPD-based dye, using spectrophotometers (spec) or titration. Test strips are also commonly used.

Future direction requires an integration of two knowledge gaps:

- Microbiological knowledge on the disinfection efficacy of halogens or other disinfection methods such as ozonation, UV $+\mathrm{H}_{2} \mathrm{O}_{2}$, and filtration (i.e. ability to achieve a 3-log reduction between client turnovers) under high salinity conditions. This was discussed previously in the introduction.

- The focus of this study was chemical testing monitoring for compliance through standardized testing methods to ensure safety and adequate disinfection

Due to the lack of microbiological studies focusing on contact time, health authorities are mandating 3-5 ppm of free chlorine as an interim measure as per provincial guidelines (4). As previously stated, Epsom salts provide inadequate disinfection, especially for gram-positive Enterococci, which highlights the importance of chlorination as a primary control measure. This supports the provincial health guidelines' mandate; thus, determination of suitable testing methodologies is instrumental for enforcement and compliance.

\section{METHODOLOGY}

The previous report by NSF demonstrated that LaMotte InstaTest ${ }^{\mathrm{TM}}$ chlorine strips have a low percentage recovery but were the most consistent out of the three methods tested. However, preliminary pilot studies demonstrated that chlorine strips do not have the required accuracy to quantitatively determine how salinity affects measured readings of free chlorine, especially at lower concentrations of chlorine. Thus, the Hach Pocket Colorimeter ${ }^{\mathrm{TM}}$ II was used in lieu of chlorine test strips. The colorimeter uses a chemicalbased method of testing - a powder, known as DPD $(N, N$-diethyl-p-phenylenediamine) reacts with free chlorine to form a dye. The intensity of the colour is proportional to the amount of free chlorine present; therefore, the colorimeter is calibrated to measure the transmissivity of the solution and convert it to a reading of free available chlorine (in ppm) (16).

The methods are split into four stages: pre-dilution, preparation of diluent, final dilution, and measurement of free available chlorine.

\section{A. Pre-dilution of sodium hypochlorite}

$5.25 \%$ sodium hypochlorite (Clorox ${ }^{\oplus}$ Original Bleach) was serially diluted a thousand-fold to yield a 52.5 ppm solution. This was accomplished via three separate 1 -in-10 dilutions $(10 \mathrm{ml}$ in $90 \mathrm{ml})$.

\section{B. Preparation of the diluent:}

USP-grade magnesium sulfate $\left(\mathrm{MgSO}_{4}\right)$ was added to a solution of water to yield a specific gravity of 1.2, then kept at a water bath set to $34^{\circ} \mathrm{C}$. The formulation is based on $0.6 \mathrm{~g}$ of $\mathrm{MgSO}_{4}$ per every $\mathrm{ml}$ of water based on a pilot study conducted prior to the experiment. 
TABLE 2. Amount of $\mathrm{MgSO}_{4}$ (s) dissolved to yield a S.D. of 1.2

\begin{tabular}{lllll}
\hline $\begin{array}{l}\text { Amount } \\
\text { of } \mathrm{MgSO}_{4} \\
\text { added }\end{array}$ & $\begin{array}{l}\text { Volume } \\
\text { of water }\end{array}$ & $\begin{array}{l}\text { Ratio of } \\
\mathrm{MgSO}_{4} \\
\text { (g) to } \mathrm{ml} \\
\text { of water }\end{array}$ & $\begin{array}{l}\text { Specific } \\
\text { density } \\
\text { (S.D.) }\end{array}$ & $\begin{array}{l}\text { Corrected } \\
\text { specific } \\
\text { density }\end{array}$ \\
20 & 100 & 0.2 & $<<1.10$ & $<<1.10$ \\
60 & 120 & 0.5 & 1.100 & 1.105 \\
80 & 120 & 0.6 & 1.215 & $\mathbf{1 . 2 2 0}$ \\
\hline
\end{tabular}

The specific density was tested via a hydrometer, calibrated to measure solutions at a temperature of $15.6^{\circ} \mathrm{C}\left(60^{\circ} \mathrm{F}\right)$. However, the solution tested was at $34^{\circ} \mathrm{C}\left(93^{\circ} \mathrm{F}\right)$. Thus, an S.D. of 0.005 needed to be added to the original reading to compensate for the temperature difference. Based on the pilot study, a ratio of $0.6 \mathrm{~g}$ of $\mathrm{MgSO}_{4}$ per $1 \mathrm{ml}$ of water yielded an appropriate specific density of 1.220 (Table 2). The solution was nearly saturated, and required 3-4 cycles of sonication and physical mixing before fully dissolving.

\section{Final Dilution}

The final dilution follows the pre-dilution. The difference is that final dilutions were made using water or magnesium sulfate (S.G. 1.2) at a temperature of $34^{\circ} \mathrm{C}$ to achieve the desired ppm. This yielded two solutions with identical concentrations of chlorine, one with salt and one without. The magnesium sulfate was only added at the final dilution step, minimizing any interactions between free available chlorine and the salt prior to testing.

\section{Colorimeter}

The chlorine level was measured for free chlorine using the USEPA DPD Method (DOC316.53.01449) with the HACH Pocket Colorimeter (17). In brief, the solution to be tested was poured into a 5 -ml plastic cuvette. Four packets of DPD powder (for a 5-ml sample) was added to the solution, then shaken continuously for 20 seconds. The sample is placed in the colorimeter cell holder, then measured for free available chlorine content. The readings are compared between the non-salt solution and the salt-solution, and a ratio is derived.

\section{E. Paired Reading}

Each reading was based on the measured chlorine level (without salt) divided by the chlorine level (with salt), leading to a percentage recovery.

$$
\begin{aligned}
& \text { Percentage recovery } \\
& =\frac{\text { Measured FAC (No salt) }}{(\text { Measured FAC }- \text { salt })} \times 100 \%
\end{aligned}
$$

\section{F: Other considerations:}

$\mathrm{pH}$ : Regulation of $\mathrm{pH}$ is not considered in the methods as the objective of the study is to determine the amount of free chlorine, which is not affected by $\mathrm{pH}$. Free chlorine is the net sum of hypochlorous acid and hypochlorite ion. While $\mathrm{pH}$ affects the ratio of the two by virtue of equilibrium chemistry, the net sum remains constant (18).

Control sample: The control samples contained either tap water or $40 \% \mathrm{MgSO}_{4}$ (S.D. 1.2) adjusted to a temperature of $34^{\circ} \mathrm{C}$. They served as a "blank" for the colorimeter.

\section{Density of magnesium sulfate solution}

The specific gravity (relative to water) of magnesium sulfate solutions in industry-standard float tanks is 1.2. Adding $20 \mathrm{~g}$ to $100 \mathrm{ml}$, however, does not result in a specific gravity of 1.2 due to liquid displacement from addition of the solid. The amount of $\mathrm{MgSO}_{4}$ required was determined by a pilot study, and confirmed using a hydrometer (Fig. 2).

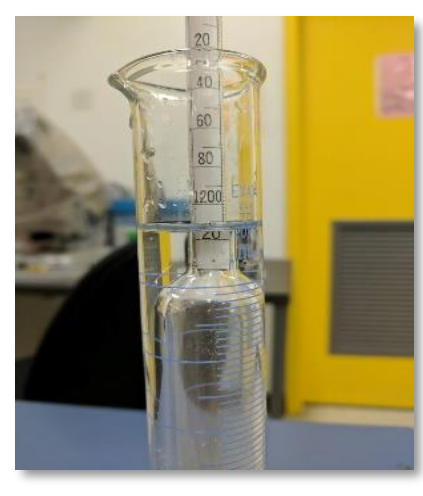

FIG 2. Hydrometer used in study 


\section{STATISTICAL ANALYSIS}

Three statistical tests were employed sequentially. The first involved a paired t-test between measured free chlorine readings with and without salt, to determine if $\mathrm{MgSO}_{4}$ quenches the colorimetric readout. Secondly, a dose-response relationship was delineated to characterize how increasing the concentration of hypochlorite affected the measured free chlorine reading in salt solutions. Lastly, a linear regression model was fitted between the paired FAC measurements with and without salt.

\section{EFFECT OF SALT ON MEASURED FAC}

Each data point is based on measured free chlorine readings from two solutions - one with salt and one without - at the same concentration of actual chlorine. An initial one-sided paired t-test was performed in NCSS to determine if there is a statistically significant difference between salt readings and non-salt readings under the same conditions. The data was nonparametric; thus, the Wilcoxon Signed-Rank Test was used. There was a paired difference with a p-value of 0.00 and $\mathrm{H}_{0}$ was rejected. $\left(\mathrm{H}_{0}\right.$ : there is no statistically significant difference between salt and non-salt readings at the same concentration of chlorine; $\mathrm{H}_{\mathrm{a}}$ : there is a statistically significant difference between salt and non-salt readings at the same concentration of chlorine)

TABLE 3. Mean percentage recoveries based on expected PPM

\begin{tabular}{lll}
\hline Expected PPM & $\begin{array}{l}\text { Mean Percentage } \\
\text { Recovery (\%) }\end{array}$ & $\begin{array}{l}\text { Sample Size } \\
\text { (n) }\end{array}$ \\
1 & 62 & 3 \\
2 & 85 & 4 \\
3 & 79 & 7 \\
4 & 78 & 7 \\
5 & 72 & 8 \\
6 & 75 & 3 \\
8 & 82 & 6 \\
\hline
\end{tabular}

The percentage recoveries (measured $\mathrm{FAC}_{\text {salt }} /$ measured $\mathrm{FAC}_{\text {no-salt }} \mathrm{x} 100 \%$ ) were averaged at each concentration level. The data provides us with an overview of the range of percentage recoveries that can be found, from 0.62 to 0.85 . The standard deviation for all samples $(n=39)$ was 0.11 , with a mean percentage recovery of $77 \%$.

\section{DOSE-RESPONSE RELATIONSHIP}

Additional tests including ANOVA were utilised to better characterize how free chlorine readings in salt respond to increasing concentrations of bleach in the solution.

Inferential statistics were employed to test the following null and alternative hypotheses:

$\mathrm{H}_{0} \quad$ There is no statistical difference between the medians of measured chlorine at 1, 2, 3, 4, 5, 6 , and $8 \mathrm{ppm}$ of theoretical chlorine

$\mathrm{H}_{a} \quad$ There is a statistical difference between the medians of measured chlorine at 1, 2, 3, 4, 5, 6 , and 8 ppm of theoretical chlorine

An increase in the theoretical chlorine concentration should result in an increase in measured chlorine in the Epsom salt. If there is an appropriate "doseresponse" pattern present, then further statistical analyses including linear regression can be conducted to derive a conversion factor. 


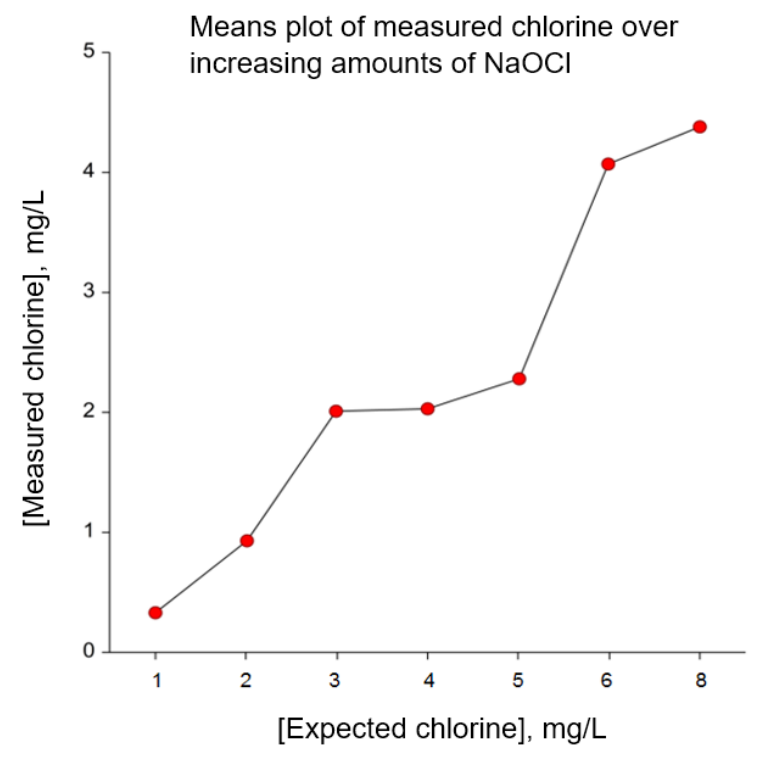

FIG 3. The means plot of measured concentration of chlorine versus increasing concentrations of expected chlorine (ppm)

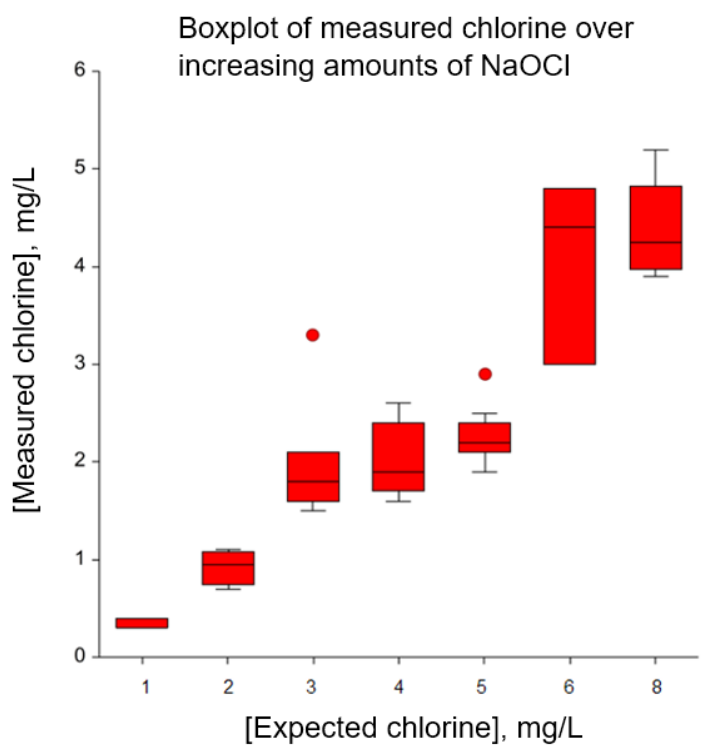

FIG 4. Boxplot of measured chlorine over increasing amounts of bleach (sodium hypochlorite). NOTE: $\mathrm{x}$-axis not to scale.

Fig. 3 demonstrates that as the amount of bleach is increased, the measured reading of free chlorine also increases. A boxplot summary (Fig. 4) delineates the variance in each group. As shown the higher concentrations $(6-8 \mathrm{ppm})$ of chlorine appear to have higher IQRs.

The Kruskal-Wallis test was conducted due to the data being non-parametric with non-equal variances. It concluded that the $\mathrm{p}$-value was 0.00003 , significantly lower than the alpha threshold of $\alpha=0.05$. The $\mathrm{H}_{0}$ was rejected, leading to the conclusion that the difference between medians is statistically significant. Scheffe's multiple comparison test provided further insight into which medians were different. The colorimeter was not able to derive statistically significant readings between 1 and 2 ppm chlorine solutions; between 3,4, and 5 ppm solutions; and between 6 and 8 ppm solutions.

\section{REGRESSION ANALYSIS}

$\mathrm{H}_{0}$ was rejected in the Kruskal-Wallis test earlier, indicating that increasing levels of bleach do result in increased levels of measured chlorine in Epsom salt solutions. It was then suitable to utilize linearregression to determine if a feasible correlation between measured chlorine (with salt) and measured chlorine (without salt) added, and to allow floatation tank operators and health inspectors to utilize a conversion factor.

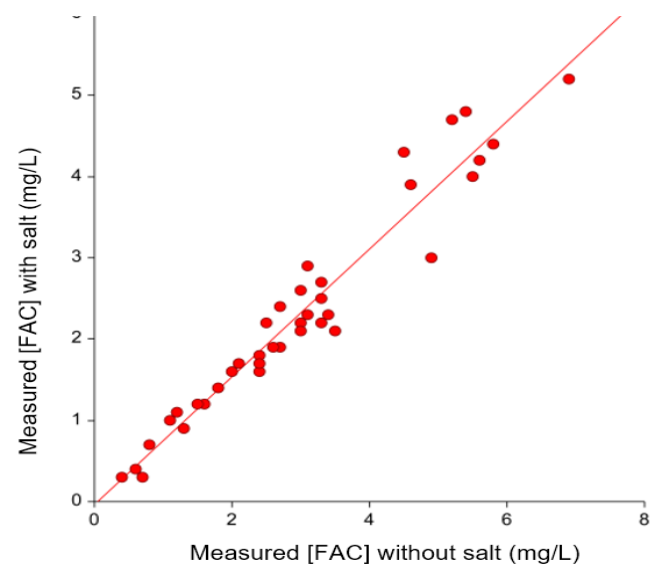

FIG 5. Linear regression model of measured chlorine with salt vs. measured chlorine without salt.

A linear model with the equation [Measured $\mathrm{FAC}]_{\text {salt }}$ $=-0.0319+0.6958 *[\text { Measured FAC }]_{\text {no-salt }}$ can be derived, with a statistically significant slope. The intercept is not statistically significant, as should be expected as a 0 FAC solution was used as the blank.

The correlation (0.9699) and $\mathrm{R}^{2}$ value (0.9407) are also high, indicating that the linear model is strong (Fig. 5). 
The coefficient of determination of 0.9407 indicates that the data fit well with the regression line, and that $94 \%$ of the response data's variability around the mean can be explained by the model (19).

\section{CORRECTION FACTOR}

A conversion factor may be derived as follows:

$y=m x+b$

$x=\frac{y-b}{m}$

When applied to study data:

$y=0.7856 x-0.0319$

$x=\frac{y+0.0319}{0.7856}$

$\rightarrow$ Actual chlorine $=\frac{\text { measured }[\mathrm{Cl}]}{0.7856}$

${ }^{*}$ Note: The y-intercept, -0.0319 , was omitted because it was not statistically significant*

\section{DISCUSSION}

\section{Findings from Study}

The quantification of free available chlorine (FAC) in high salinity environments is feasible with a Hach Pocket Colorimeter $\mathrm{II}^{\oplus}$, and responds to increasing amounts of bleach added to a solution. Previous research has shown that there is high variability in using DPD-based methods. The author argues that the use of a Pocket Colorimeter $\mathrm{II}^{\oplus}$ manages to address the issue of variability, so long as the standard method is adhered to and that the DPD be given sufficient time to react with the free chlorine.

This study has demonstrated two key points:

(1) There is a dose-response relationship between the amount of free chlorine in a saturated $\mathrm{MgSO}_{4}$ solution and the measured chlorine reading. Solutions diluted to 1-2 ppm (low), 3-5 ppm (medium), and 6-8 ppm (high) had statistically significant differences in their readings as per ANOVA post-hoc analyses. In practice, this system works for health inspectors and public health practitioners seeking to measure a general range of free chlorine in floatation tanks (low: 1-2, medium: 3-5; high: 6-8 ppm).

(2) Salt solutions have a lower percentage yield of free chlorine compared to non-salt solutions. The aforementioned correction factor was derived to account for this lower yield.

\section{Additional Observations}

The expected measured FAC yield in a salt solution is approximately $78 \%$ compared to a solution with no salt, provided that the chlorine is tested 2 minutes after being added. If the chlorine has been in the solution for over 5 minutes, the initial percentage yield may be lower ( 40\%). However, it increases back to the expected yield if the tester waits for approximately 5-7 minutes for the DPD (dye) to react with the free chlorine (i.e. wait for 5-7 minutes before applying the correction factor.

\section{Integration with other research findings}

This study was compared against Tsang (2015) and NSF (2014).

\section{Comparison with Environmental Health Study from Tsang (2015)}

Tsang's original study on the accuracy of swimming pool test kits evaluated the LaMotte ColorQ, Hach Titration test kit, and the Taylor Chlorine Test Kit -3 commonly used and inexpensive testing kits used by health inspectors (13). The study demonstrated that while $\mathrm{pH}$ can be measured consistently, levels of free chlorine and total chlorine often fluctuated to significant levels. Conversely, this study has demonstrated that the Hach Pocket Colorimeter II $^{\circledR}$ is a more precise and accurate device that can differentiate between low, medium, and high concentrations of free chlorine in Epsom salt solutions, and is a valid and reliable tool in the workplace. 


\section{Comparison with NSF Study}

The NSF study in 2014 conducted by Schaefer et al. also stated that the Hach DPD AccuVac ${ }^{\circledR}$ method of testing had significant standard deviations, especially at the 2-ppm level (Fig. 6) (15). The study suggested that the DPD AccuVac method, although having higher percentage recovery, was inconsistent and unreliable. This study was also based on DPD, although a different apparatus (Pocket Colorimeter ${ }^{\oplus}$ II) and standard procedure was used. As opposed to the AccuVac, analysis via ANOVA has demonstrated that the Pocket Colorimeter II $^{\mathrm{TM}}$ could produce statistically significant difference in readings between low, medium, and high formulations of chlorine in $\mathrm{MgSO}_{4}$.

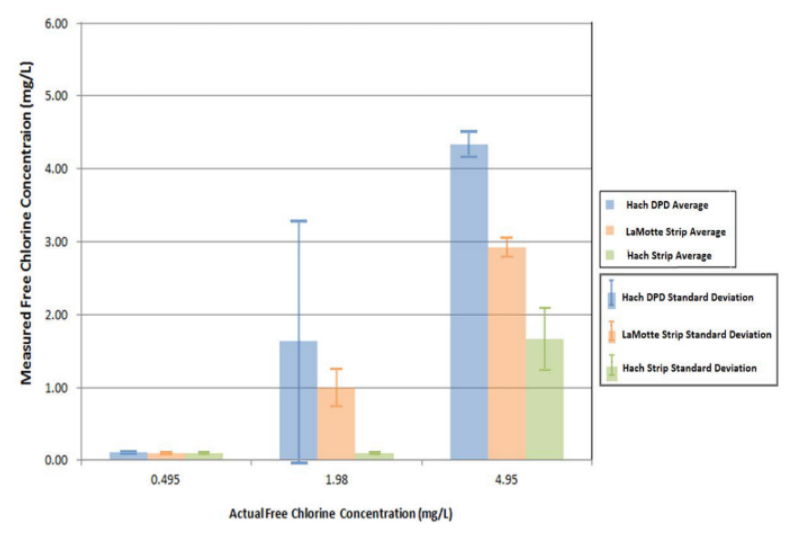

FIG 6. The NSF study in 2014 showed that the Hach AccuVac Method had a very high standard deviation at $2 \mathrm{mg} / \mathrm{L}$.

The high standard deviation of the AccuVac contrasts with the usable variance in this study's results using the Hach Pocket Colorimeter II ${ }^{\circledast}$.

\section{Potential Mechanisms}

There are a variety of reasons that could explain why Epsom salts decrease the colorimetric yield. It was observed that the DPD did not immediately dissolve in the Epsom salt solution, and that the characteristic magenta dye took several minutes to form. This could be due to the high osmolarity and ionic strength of the solution. Although the exact mechanism is unknown, it is possible that the magnesium or sulfate ions could impede the reaction of DPD with free chlorine through the following ways:
Physical: The ionic strength of the solution occupies numerous water molecules, preventing them surrounding the DPD dye and dissolving it. If the DPD dye is not dissolved, it may not be able to react with the hypochlorous acid or hypochlorite ion to form the magenta-colored complex.

Chemical: Magnesium or sulfate ions may interact with the polar amine group in DPD, preventing it from reacting with the free chlorine (Fig. 7). Alternatively, magnesium ions may bind to the hypochlorite ion, reducing the amount of FAC.

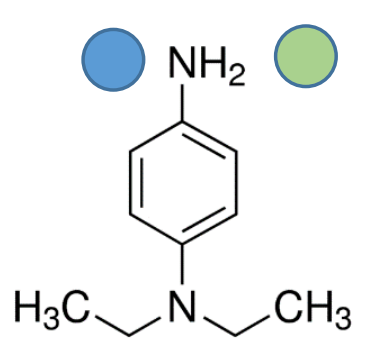

\section{LEGEND}

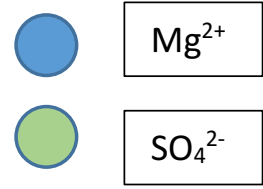

FIG 7. Potential polar-ionic interactions between DPD and magnesium sulfate (20)

\section{Validity of Results}

Within the timeframe of this study, every effort has been made to maximize validity to actual floatation tank scenarios. This included conducting several pilot studies:

- A side-study was done to determine the correct amount of magnesium sulfate to add in water to yield a solution with a specific density (S.D.) of 1.22 , which is at the lower range of the industry standard (21)

- A hydrometer was used to confirm the S.D. as 1.220 prior to usage

- A water bath, ultrasonic shaker, and mortar and pestle were used to ensure that the magnesium sulfate was completely dissolved prior to testing with DPD

- Free chlorine and the Epsom salt solution were only mixed together at the final dilution step, ensuring that there were no prior 
interactions between the two that could have compromised the results. All testing was done 2 minutes after the formulation was made

- Testing was done per the USEPA standard method for quantification of free chlorine, compiled by the Hach company (17)

- Temperatures were kept constant at $34^{\circ} \mathrm{C}$ in a water bath, which is the same temperature floatation tank solutions are kept it

One methodological limitation was that the water was not actively circulating due to budget constraints. Floatation tanks typically employ a pump to circulate water through a filter; if circulation affects the rate at which the free chlorine reacts with the salt, then the validity of the study may be reduced. However, there is currently no evidence to suggest that this occurs.

Thus, the study should be able to be extrapolated to the testing of chlorine in most floatation tanks.

\section{LIMITATIONS}

Limitations revolved primarily around the need for more data points, and the timing of when to test for chlorine after the formulation has been made. The following points elaborate further on these limitations:

\section{Data Points}

The study will benefit from an increased number of data points. Each data point is laborious; thus, some concentrations of free chlorine are left underrepresented (e.g. 1-2 ppm, 6-8 ppm).

\section{Timing}

The study also heavily focuses on measurement of chlorine 2 minutes after the solution was formulated, and does not extensively factor in long-term interactions between the chlorine and the magnesium sulfate. Floatation tanks, especially those that do not continuously feed free chlorine into the system, would have free chlorine suspended for much longer than 2 minutes. $\mathrm{MgSO}_{4}$ may play a role in sequestering the free chlorine. The study may not be valid for free chlorine that has been in the floatation tank for an extended period.

A side-study was conducted to address this, demonstrating that the same yield can be provided between solutions 2 minutes old and 20 minutes old. However, in older solutions, the dye requires more time to react with the free chlorine ( $\sim 5-7$ minutes) to produce an equivalent readout.

\section{KNOWLEDGE TRANSLATION}

The study suggests that the Pocket Colorimeter $\mathrm{II}^{\circledast}$ is a feasible and effective method of estimating the amount of free chlorine in a floatation tank environment. Conversely, it does not endorse the use of test strips or the LaMotte ColorQ, which have not been tested for accuracy in measuring salt solutions.

Prior to this study, there has been a lack of confidence in the industry regarding accurate and consistent testing of free chlorine levels in floatation tank environments. This study will be useful for public health inspectors and operators seeking a more accurate means of quantifying free chlorine levels in float tanks using a Pocket Colorimeter II $^{\text {}}$. Results strongly suggest $(\mathrm{p}=0.00003)$ a positive correlation between the amount of hypochlorite in a saturated $\mathrm{MgSO}_{4}$ solution and the free chlorine reading on the colorimeter. Furthermore, the study has shown that a conversion factor can be derived between measured chlorine in salt solutions versus non-salt solutions (see B1. Findings from study).

This will assist inspectors in determining the range of free chlorine in a floatation tank, whether it be low (1$2 \mathrm{ppm}$ ), medium (3-5 ppm), or high (6-8 ppm). Health inspectors will be able to use this information to determine if a tank is microbiologically safe, and provide suggestions to operators if the chlorine concentration is outside of range of 3-5 ppm as recommended by the BC Floatation Tank Guidelines. The BC Floatation Tank Guidelines may also include the colorimeter as part of a series of recommended methods of quantifying FAC in Epsom salt water. 


\section{FUTURE RESEARCH}

Further research should be conducted in the industry to verify the accuracy of the conversion formula listed earlier, and determine if it can be programmed into future colorimeters. Additional studies may include the following:

- Sampling from floatation tanks under the assumption that the operator is aware of the amount of free chlorine added to the tank. The formula can be applied and determined for accuracy and applicability in the field.

- Delineate how free chlorine reacts with magnesium sulfate over time to determine whether the magnesium sulfate irrevocably deactivates or sequesters free chlorine, under different concentrations (ppm). The effect of DPD-readings over time in Epsom salt solutions also needs to be more extensively characterized.

- Testing of other used halogens including free bromine instead of chlorine $\left(\mathrm{HOBr}, \mathrm{OBr}^{-}\right)$ under high salinity conditions

\section{CONCLUSIONS}

Although there have been no reported outbreaks or adverse effects from the use of floatation tanks, a lack of epidemiological data does not remove the possibility of transmissible waterborne diseases. It is important to be cognizant of potential risks. Health inspectors are mandated to anticipate and evaluate the risk of waterborne illnesses in the community, and to implement measures to safeguard against the public against transmissible disease (22). The findings from this study will assist both health inspectors and floatation tank operators in estimating the amount of free chlorine residual in a tank, allowing them to optimize the level of active disinfection. In other words, the results will allow inspectors to utilize the Pocket Colorimeter II $^{\circledast}$ from Hach to estimate low, medium, or high levels of free available chlorine through the application of a conversion factor and formula.
From a more macroscopic perspective, additional studies need to be conducted (see Future Research) to further corroborate this study, so that the industry can move forward to better characterize and quantify free chlorine levels in floatation tanks. Initiatives, including programming a conversion formula and developing calibration curves for other chemicals will further advance our understanding of how DPD and halogens behave in Epsom salt solutions.

\section{ACKNOWLEDGEMENTS}

The author would like to acknowledge Dr. Helen Heacock and Vanessa Karakilic for their guidance and knowledge on past projects; Shelly Beaudet, Senior Environmental Health Officer, for insight on current public health practices at $\mathrm{VCH}$ regarding floatation tanks; and Dr. Angela Eykelbosh (NCCEH) for mentorship, guidance, and past reports pertaining to chlorine and microbiological testing.

Environmental Health Faculty members including Gary Tam and Martin MacLeod have provided further understanding into pool chemistry and the nature of floatation tank inspections.

Frederick Shaw (Laboratory Manager, Environmental Health Faculty at the BC Institute of Technology) has provided numerous hours in supervision, technical assistance, equipment, and lab space towards this study. His assistance is greatly appreciated. Lastly, the lead author would like to express his gratitude towards Ken Keilbert and Melinda Lee from the Food Technology Programme at BCIT for lending a hydrometer for the study.

\section{ABBREVIATIONS}

FAC Free Available Chlorine

FAC $_{\text {salt }} \quad$ FAC tested under floatation tank conditions

$\mathrm{FAC}_{\text {no-salt }} \mathrm{FAC}$ tested without Epsom salts

DPD N,N,Diethyl-p-phenylenediamine.

Colorimetric dye for testing chlorine

$\mathrm{MgSO}_{4} \quad$ Magnesium sulfate, USP (Epsom salts) 


\section{CONFLICTING INTERESTS}

The authors declare that there are no competing interests in the study.

\section{REFERENCES}

1. Beaudet S, Eykelbosh A. Float Tanks : Review of Current Guidance and Considerations for Public Health Inspectors. 2016;(July):1-8.

2. BBC News. Why Do People Use Blogs? 2016 Feb; Available from: http://www.bbc.co.uk/news/magazine-35521560

3. Zen Float Company. Float Tank Filtration Design [Internet]. Available from: http://www.zenfloatco.com/blogpages/2014/6/7/filtration-design-on-the-new-zen-tank

4. BC Ministry of Health. GUIDELINES FOR FLOATATION TANKS. 2016.

5. NSF International. Recreational Water Program Component Certification Specification for Public Use Spa, Swim Spa , Hot Tub or Related Equipment. Available from: http://www.nsf.org/newsroom_pdf/11804.pdf

6. Vital M, Stucki D, Egli T, Hammes F. Evaluating the growth potential of pathogenic bacteria in water. Appl Environ Microbiol. 2010;76(19):6477-84.

7. Donofrio R. Organism Time Kill in Float Lab Water. Ann Arbor, MI; 2012.

8. Bechanko R, Schindler B. Organism Viability Testing in Epsom Salt and Control Solution. Ann Arbor, MI; 2015.

9. Environmental Protection Agency. CT Tables. EPA Guid Man LT1ESWTR Disinfect Profiling Benchmarking [Internet]. 2003;93-111. Available from: www.epa.gov/ogwdw/mdbp/pdf/profile/lt1profiling.pd

10. Nadolny E, MacDougall C. Evidence Brief : Risk of Infection in the Use of Floatation Tanks [Internet]. 2016. Available from:

https://www.publichealthontario.ca/en/eRepository/EB_Floa tation_Tanks_Infection_Risk.pdf

11. Eykelbosh A, Beaudet S. Float Tanks : Considerations for Environmental Public Health. 2016;(JULY):1-14.

12. Taylor Technologies. PUTTING FAS-DPD TO THE TEST: THE LATEST TREND IN CHLORINE ANALYSIS [Internet]. 2016. Available from: https://www.taylortechnologies.com/ChemistryTopicsCM.A SP ?ContentID $=11$
13. Tsang F, Sidhu B. Accuracy of Swimming Pool Test Kits. BCIT Environ Heal J. 2015;1-11.

14. Pohl M. Tools for Environmental Health. NEHA. 1999 May;

15. Schaefer K. Recovery analysis of free and total chlorine measurement methods in high $\mathrm{MgSO} 4$ solution. Ann Arbor, MI; 2014.

16. Hach Company. Pocket Colorimeter II, Chlorine (Free and Total) [Internet]. Water Quality Products For Government Buyers. 2017. Available from: https://www.hach.com/pocketcolorimeter-ii-chlorine-free-andtotal/product $? \mathrm{id}=7640442953$

17. Hach Company. Chlorine, Free and Total, High Range USEPA DPD Method. 2014;

18. Hydro Instruments. Forms of Chlorine in Water [Internet]. Available from: http://www.hydroinstruments.com/page.aspx ?page_id=104

19. Frost J. Regression Analysis: How Do I Interpret R-squared and Assess the Goodness-of-Fit? [Internet]. The Minitab Blog. 2013. Available from: http://blog.minitab.com/blog/adventures-in-statistics2/regression-analysis-how-do-i-interpret-r-squared-andassess-the-goodness-of-fit

20. Sigma-Aldrich. N-N-Diethyl-p-phenylenediamine [Internet]. Available from:

http://www.sigmaaldrich.com/catalog/product/aldrich/26151 3 ?lang=en\&region $=$ US

21. Jahromi A, Leibner S, Perry G, Talley G, Wasserman D. US Float Tank Standard. :120.

22. City of Richmond. Personal Service Establishments Environmental Health [Internet]. 2017. Available from: http://www.richmond.ca/safety/environment/personal.htm 